\title{
PEMBERDAYAAN MASYARAKAT DESA MENGKIANG MELALUI PROGRAM JAMBAN PERCONTOHAN
}

\author{
Marlenywati $^{\# 1}$, Abduh Ridha ${ }^{* 2}$, Hanum Mukti Rahayu ${ }^{\# 3}$ \\ ${ }^{\# 1}$ Program Studi Kesehatan Masyarakat FIKES Universitas Muhammadiyah Pontianak, Jalan A. Yani No. \\ 11 Pontianak \\ ${ }^{1}$ emai.marlenywati@unmuhpnk.ac.id \\ ${ }^{\# 2}$ Program Studi Kesehatan Masyarakat FIKES Universitas Muhammadiyah Pontianak, Jalan A. Yani No. \\ 11 Pontianak \\ ${ }^{2}$ email.4bduhrldha@gmail.com \\ ${ }^{\# 3}$ Program Studi Biologi FKIP Universitas Muhammadiyah Pontianak, Jalan A. Yani No. 11 Pontianak \\ ${ }^{3}$ email. hanumunmuhptk@gmail.com
}

\begin{abstract}
Abstrak
Desa Mengkiang terletak di Kecamatan Kapuas Kabupaten Sanggau yang berjarak 175 km dari ibukota provinsi Kota Pontianak. Masalah utama yang dihadapi masyarakat adalah masih rendahnya rumah tangga yang menerapkan rumah sehat $(\mathbf{5 1 , 4 5 \%})$ dan memiliki jamban sehat $(\mathbf{3 7 \%})$. Masyarakat lebih banyak melakukan buang air besar (BAB) di lanting yang terdapat di sungai. Tindakan tersebut dapat mengakibatkan sungai tercemar oleh kotoran dan meningkatkan risiko penyakit berbasis lingkungan.

Target kegiatan adalah penerapan IPTKES melaui kegiatan program jamban percontohan sehingga dapat dipergunakan sebagai sarana pembuangan tinja keluarga. Pelaksanaan kegiatan dilakukan bertahap; dimulai dari penyuluhan mengenai jamban sehat, pendataan jamban sehat keluarga melalui pendampingan Program Indonesia Sehat Pendekatan Keluarga (PIS-PK), pelaksanaan tabungan jamban (tanjan) dan komitmen bersama melakukan renovasi jamban umum desa menjadi jamban percontohan.
\end{abstract}

Kata Kunci - jamban percontohan, penyuluhan, pendataan dan tabungan jamban

\section{PENDAHULUAN}

Indeks Pembangunan Masyarakat (IPM) Indonesia berdasarkan Laporan UNDP Tahun 2016 berada diperingkat 113 dari 188 negara dan termasuk kategori pembangunan manusia menengah ${ }_{[1]}$. Tahun 2016 seperti yang dikutip Harian Tribun Pontianak, Kalimantan Barat menempati urutan IPM ke-29 dari 33 provinsi yang ada di Indonesia, sedangkan Kabupaten Sanggau menempati urutan ke-12 dari 14 kabupaten/kota yang ada di Provinsi Kalimantan Barat $^{[2]}$.

Urutan tersebut menempatkan kategori pembangunan di Kabupaten Sanggau termasuk kedalam kategori rendah dan perlu mendapat perhatian dari semua pihak baik pemerintah maupun masyarakat.. Selain itu juga untuk mendukung tujuan pembangunan berkelanjutan atau Sustainable Development Goals (SDGs) yang poinnya antara lain berisikan kehidupan layak dan kesejahteraan, pendidikan yang berkualitas, meningkatkan pekerjaan layak dan pertumbuhan ekonomi serta meningkatkan sanitasi dan air bersih ${ }^{[1]}$.

Salah satu kecamatan yang ada di Kabupaten Sanggau adalah Kecamatan Sanggau Kapuas. Kecamatan Sanggau Kapuas memiliki luas wilayah sebesar $1.382 \mathrm{Km}^{2}$ atau $10.75 \%$ dari total keseluruhan wilayah Kabupaten Sanggau ${ }^{[3]}$. Kecamatan Kapuas juga merupakan kecamatan dengan jumlah desa/kelurahan terbanyak yaitu 19 kelurahan/desa termasuk Desa Mengkiang ${ }^{[4]}$.
Data Puskesmas Sanggau Kapuas tahun 2016, masalah yang terdapat di Kecamatan Sanggau Kapuas rumah tangga yang menerapkan perilaku hidup bersih dan sehat (PHBS) sebesar 32\%, penduduk yang memiliki sarana air minum layak sebesar $44 \%$, penduduk yang memiliki jamban sehat $37 \%$. Disamping itu semua desa di belum diterapkan sanitasi total berbasis masyarakat $(\mathrm{STBM})^{[5]}$. Data Desa Mengkiang menunjukkan bahwa Cakupan PHBS Rumah tangga baru mencapai 37,4\% . Hasil wawancara terhadap beberapa masyarakat menunjukkan bahwa masih terdapat masyarakat yang melakukan Buang Air Besar (BAB) sembarangan, tidak di Jamban atau WC yang tersedia melainkan di lanting (jamban yang terdapat di sungai). Hal ini dikarenakan kebiasaan dan merasa lebih "nyaman" melakukan BAB di lanting dibandingkan di jamban yang tersedia di rumah.

Potensi yang dimiliki oleh Desa Mengkiang adalah adanya kelompok PKK dan kader kesehatan serta aparat pemerintahan yang lengkap dalam mendukung kegiatan pemberdayaan masyarakat seperti sanitasi total berbasis masyarakat (STBM), Permasalahan kesehatan khususnya kepemilikan jamban sehat di Desa Mengkiang memungkinkan dilakukannya pemberdayaan masyarakat melalui inisiasi program jamban sehat percontohan. 



\section{TARGET DAN LUARAN YANG DICAPAI}

Target luaran yang diharapkan dalam kegiatan KKN-PPM ini adalah : penerapan program jamban percontohan melalui jamban umum desa dan memicu masyarakat untuk membangun jamban sehat di rumah masing-masing melalui tabungan jamban (Tanjan). Selain itu juga dilakukan penyuluhan mengenai jamban sehat dan pendataan rumah tangga yang memiliki jamban sehat dengan sampel sebanyak $150 \mathrm{KK}$

\section{METODE PELAKSANAAN} lain:

Metode pelaksanaan yang digunakan, antara

1. Penyuluhan mengenai Jamban Sehat, materi yang disampaikan berupa pengertian, manfaat dan indikator jamban sehat keluarga. jamban keluarga adalah suatu bangunan yang digunakan untuk membuang dan mengumpulkan kotoran sehingga kotoran tersebut tersimpan dalam suatu tempat tertentu dan tidak menjadi penyebab suatu penyakit serta tidak mengotori permukaan Menurut Depkes RI (2004), terdapat beberapa syarat Jamban Sehat, antara lain :

a) Tidak mencemari sumber air minum, letak lubang penampung berjarak 10-15 meter dari sumber air minum.

b) Tidak berbau dan tinja tidak dapat dijamah oleh serangga maupun tikus.

c) Cukup luas dan landai/miring ke arah lubang jongkok sehingga tidak mencemari tanah di sekitarnya.

d) Mudah dibersihkan dan aman penggunannya.

e) Dilengkapi dinding dan atap pelindung, dinding kedap air dan berwarna.

f) Cukup penerangan

g) Lantai kedap air

h) Ventilasi cukup baik

i) Tersedia air dan alat pembersih

2. Pelaksanaan penyuluhan jamban sehat keluarga dilakukan dengan sasaran masyarakat di dua dusun, Dusun Tokang dan Mengkiang

3. Pendataan Rumah tangga yang memiliki Jamban. Pendataan ini dilakukan bersamaan dengan penyuluhan rumah sehat. Prosesnya dilakukan observasi lingkungan rumah terhadap 150 RT di Desa Mengkiang.

4. Membangun jamban percontohan, dimana jamban tersebut merupakan jamban milik desa yang sudah tidak pernah digunakan lagi dengan alasan sudah tidak layak pakai dan memenuhi syarat.

5. Program Tabungan Jamban (Tanjan) untuk menginisiasi masyarakat membuat jamban di rumah masing-masing.

6. Pendampingan, dimaksudkan untuk membantu dan membimbing mitra kegiatan KKNPPM, yang dalam hal ini masyarakat Desa Mengkiang.

\section{IV.HASIL DAN PEMBAHASAN}

Kegiatan KKN-PPM Desa Mengkiang melibatkan sebanyak 15 mahasiswa dari berbagai lintas program studi di Universitas Muhammadiyah Pontianak diantaranya mahasiswa kesehatan masyarakat. Kegiatan KKN-PPM masalah kesehatan difokuskan pada permasalahan mengenai sanitasi lingkungan masyarakat Desa Mengkiang melalui kegiatan berikut :

\section{A. Koordinasi Kegiatan}

Kegiatan KKN-PPM di Desa Mengkiang dilaksanakan selama rentang waktu 45 hari, dimulai dari 28 Juli - 16 September 2018. Kegiatan tahap awal yang dilaksanakan adalah melaksanakan lokakarya mini desa dengan tujuan menyampaikan paparan program kesehatan yang akan dilaksanakan mahasiswa di Desa Mengkiang. Lokakarya mini dilaksanakan pada Hari Senin, 30 Agustus 2018 yang dihadiri sebanyak 30 peserta baik dari unsur pemerintahan desa seperti kepala desa, kepala dusun dan masyarakat desa. Kegiatan lokakrya mini desa diperoleh kesepakatan bersama mengenai kegiatan program kesehatan jamban sehat percontohan yang akan dilaksanakan, jadwal, bentuk serta peran dari aparat dan masyarakat dalam kegiatan.

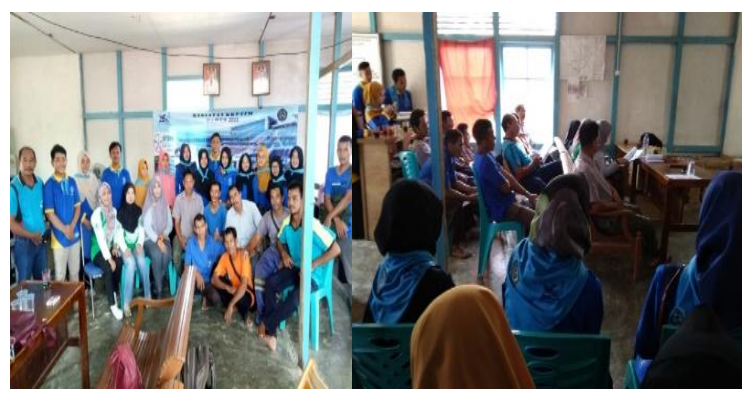

Gambar 1. Lokakarya Mini Desa Mengkiang

\section{B. Sosialisasi dan Penyuluhan}

Kegiatan sosialisasi dan penyuluhan bertujuan agar masyarakat Desa Mengkiang mengetahui dan ikut serta secara aktif dalam program kesehatan kegiatan KKN-PPM. Salah satunya adalah mengikuti penyuluhan jamban sehat yang dilaksanakan oleh mahasiswa KKN-PPM. Kegiatan dilaksanakan di 2 Dusun, yaitu Dusun Tokang dan Dusun Mengkiang. Sasaran kegiatan ini adalah kepala rumah tangga. Peserta penyuluhan di Dusun Mengkiang sebanyak 30 warga, sedangkan di Dusun Tokang sebanyak 18 warga.

Narasumber dalam kegiatan ini adalah mahasiswa peserta KKN-PPM yang berlatar belakang program studi Kesehatan Masyarakat. Mahasiswa sebelumnya telah mendapatkan pembekalan materi Jamban Sehat oleh Tim Pengabdi KKN-PPM antara lain : Abduh Ridha, SKM, M.PH dan Marlenywati, S.Si, M.KM serta didampingi oleh 

Bidan Desa Mengkiang pada saat memberikan penyuluhan.

Materi penyuluhan yang disampaikan antara lain pengertian, manfaat dan indikator jamban sehat. Selain menyampaikan materi, narasumber juga melakukan diskusi dengan masyarakat terkait kebiasaan masyarakat yang masih melakukan $\mathrm{BAB}$ sembarangan ataupun di lanting. Risiko dari melakukan BAB adalah tercemarnya air sungai oleh kotoran manusia dan meningkatkan risiko terjadinya penyakit berbasis lingkungan.

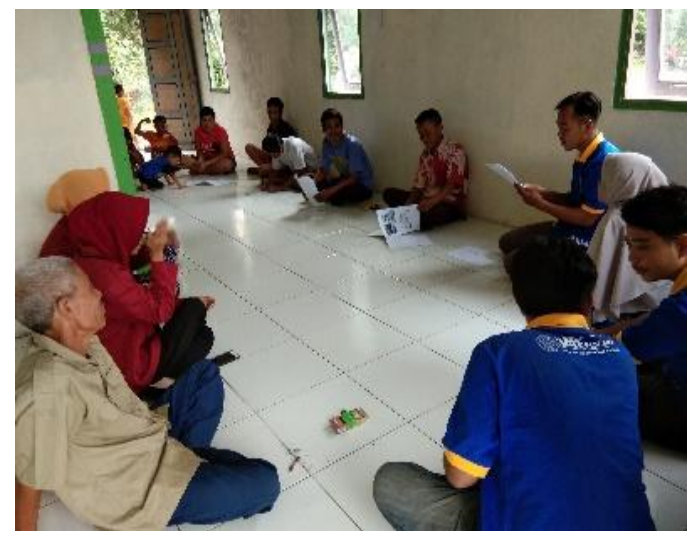

Gambar 2. Penyuluhan jamban sehat di Dusun Mengkiang dan Dusun Tokang Desa Mengkiang

\section{Pendataan Rumah Tangga yang Memiliki Jamban}

Kegiatan yang dilakukan selanjutnya adalah melakukan pendataan rumah tangga yang memiliki jamban. Kegiatan ini dilakukan bekerjasama dengan Puskesmas Sanggau Kapuas, Kab. Sanggau melalui Program Indonesia Sehat - Pendekatan Keluarga (PIS-PK). Sebelum pendataan rumah tangga yang memiliki jamban secara door to door dilakukan pembekalan oleh Tim Pengabdi KKN-PPM, Kepala Puskesmas Sanggau Kapuas Albert D. Sihotang, M.KM serta pemegang program di Puskesmas Sanggau Kapuas Yayuk Sri Indra Arianto, A.Md Keb. Sasaran rumah tangga yang didata sebanyak 150 kepala keluarga (KK). Kegiatan pendataan dilaksanakan selama 14 hari dengan sasaran sebanyak 10 - 12 KK setiap hari yang di data. Mahasiswa KKN-PPM yang terlibat melakukan observasi lingkungan rumah dan melakukan wawancara terhadap kepala keluaga. Setelah itu dilakukan penyuluhan mengenai Jamban Sehat. Rumah yang telah dilakukan pendataan dilakukan penempelan stiker pendataan rumah sehat KKNPPM serta pemberian leaflet indikator rumah sehat. Hasil pendataan diperoleh sebanyak $61 \mathrm{KK}(40,67 \%)$ dari $150 \mathrm{KK}$ yang tidak memiliki jamban di rumah.

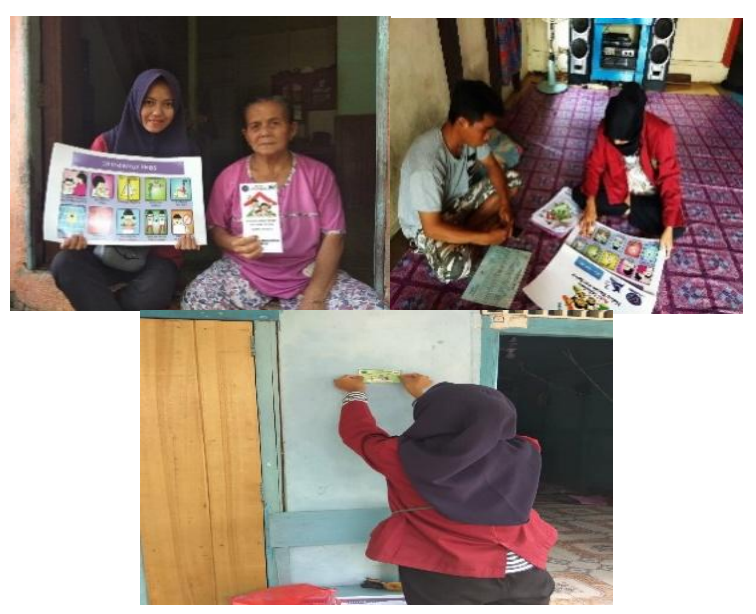

Gambar 3. Pendataan dan penyuluhan rumah sehat serta penempelan stiker rumah yang telah di data

\section{Jamban Percontohan}

Program jamban percontohan menjadi kegiatan utama dalam KKN-PPM di Desa Mengkiang. Hal ini dikarenakan masih banyak masyarakat yang tidak memiliki jamban sehingga menyebabkan BAB sembarangan. Kegiatan ini memanfaatkan jamban umum desa. Terdapat 3 jamban umum desa di lokasi yang berbeda. Untuk kegiatan jamban percontohan pemilihan lokasi jamban disesuaikan dengan kemudahan akses masyarakat. Jamban tersebut terletak di dekat poskesdes. Sebelumnya disepakati oleh masyarakat, aparat desa dan mahasiswa KKNPPM bahwa akan dilakukan renovasi jamban desa menjadi jamban percontohan.

Jamban desa yang ada sudah lama tidak dipergunakan oleh masyarakat dan tidak terawat. Beberapa bagian dari jamban tersebut ada yang rusak. Diantaranya kloset yang sudah tidak dapat dipakai, dinding dan septic tank yang bocor, tidak terdapatnya tandon air penampungan serta kondisi jamban yang bersemak.

Proses melakukan renovasi jamban dilakukan kurang lebih 1 minggu dengan melibatkan mahasiswa KKN-PPM, aparat desa dan masyarakat. Mahasiswa KKN-PPM melakukan inventaris kebutuhan untuk melakukan renovasi jamban. Sarana pendukung seperti alat tukang dan lainnya dipersiapkan oleh pihak desa. Selain itu pihak desa dan masyarakat yang tanahnya ditempati jamban percontohan juga melakukan kesepakatan. Kesepakatan dilakukan agar dikemudian hari tidak menjadi permasalahan, bahwa jamban tersebut adalah jamban umum dan dapat dipergunakan masyarakat Desa Mengkiang, tidak hanya personal. 



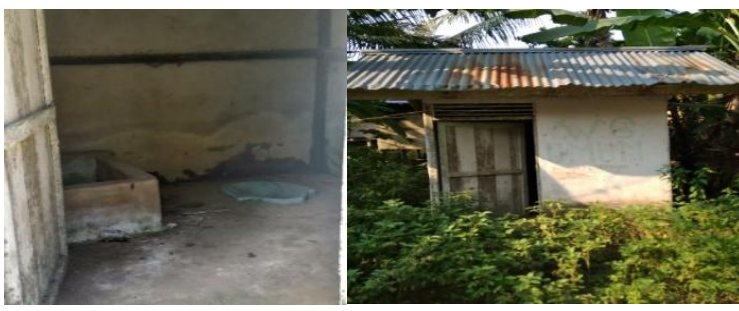

Gambar 4. Jamban Desa Sebelum Renovasi

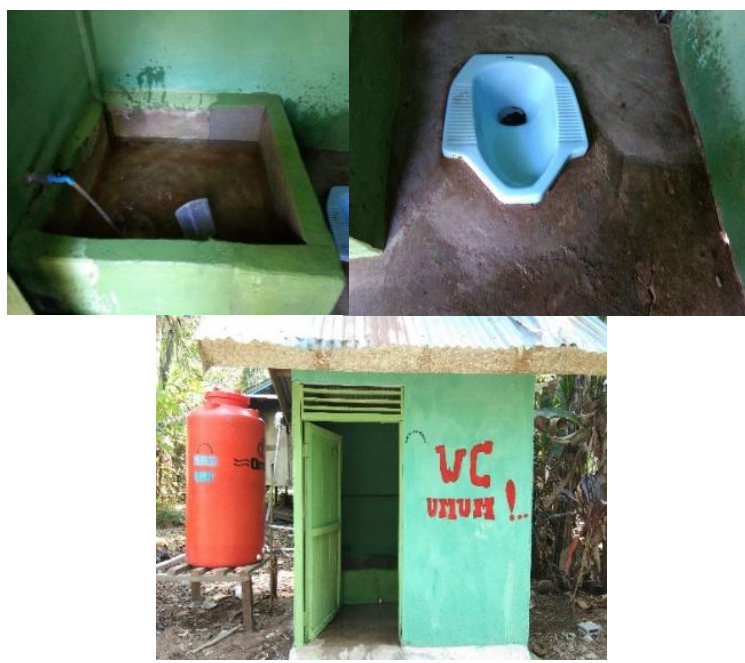

Gambar 5. Jamban Percontohan Desa Mengkiang

\section{E. Tabungan Jamban (Tanjan)}

Hasil pendataan Rumah sehat yang dilakukan mahasiswa KKN-PPM diperoleh data sebanyak 40,67\% masyarakat yang tidak memiliki jamban di rumahnya. Berdasarkan hal tersebut, mahasiswa KKN-PPM menawarkan program tabungan jamban (tanjan) masyarakat. Tahap awal kegiatan dilaksanakan sosialisasi tabungan jamban dengan sasaran ibu-ibu rumah tangga mengingat pengelolaan uang di dilakukan oleh ibu-ibu. Mekanisme pengelolaan Tanjan dilakukan oleh seorang kader kesehatan, dimana setiap keluarga yang berkomitmen untuk mengikuti Tanjan diberikan celengan atau tempat menyimpan uang. Total sebanyak 12 keluarga atau rumah tangga yang berkomitmen mengikuti tabungan jamban (tanjan). Setiap keluarga menabung di tabungan jamban tersebut setiap bulannya sesuai dengan kesepakatan bersama.

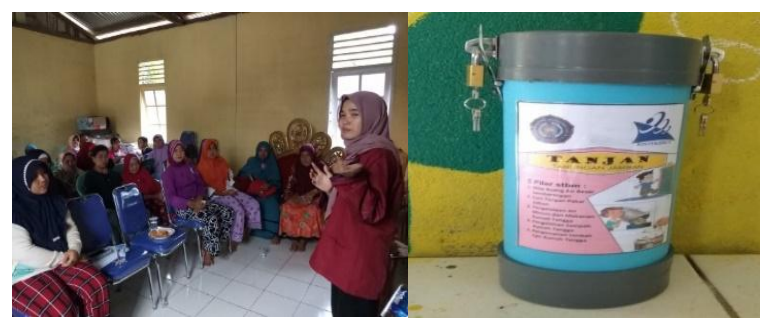

Gambar 6. Sosialisasi tabungan jamban dan bentuk tabungan jamban (tanjan)

\section{F. Pendampingan}

Pendampingan dimaksudkan untuk mengetahui penerapan ipteks oleh masyarakat. Kegiatan KKNPPM mahasiswa di Desa Mengkiang mendapatkan respon positif dari masyarakat dan aparat desa. Setiap kegiatan yang dilakukan oleh mahasiswa mendapatkan perhatian dan masyarakat antusias mengikuti kegiatan yang dilakukan oleh mahasiswa KKN-PPM. Dimulai dari kegiatan lokakarya mini, penyuluhan jamban sehat, pendataan rumah tangga yang memiliki jamban serta program jamban percontohan dan tabungan jamban. Masyarakat Desa Mengkiang antusias dan aparat desa mendukung kegiatan karena program yang ditawarkan ke masyarakat dirasa menjadi solusi dari permasalah ketersediaan jamban di rumah tangga.

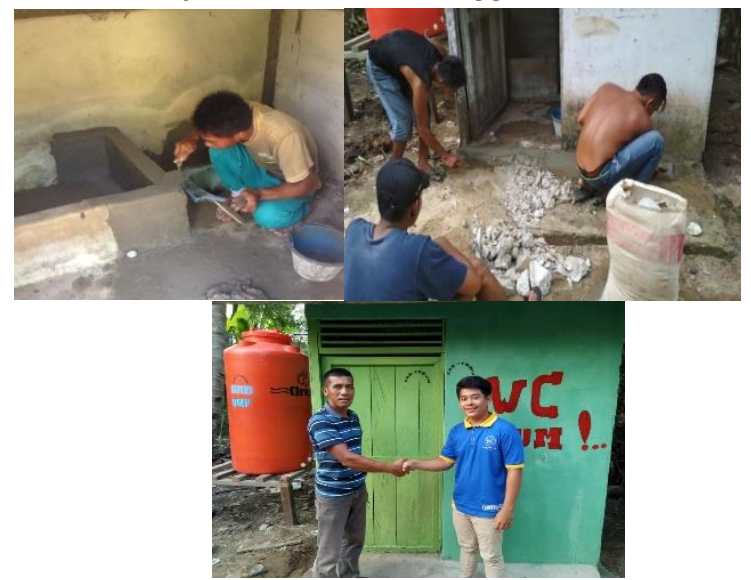

Gambar 7. Partisipasi aktif masyarakat dalam program jamban percontohan Desa Mengkiang

\section{KESIMPULAN}

1. Tahapan pelaksanaan KKN-PPM di Desa Mengkiang terkait program jamban percontohan antara lain : lokakarya mini desa, penyuluhan jamban sehat, pendataan rumah tangga yang memiliki jamban, pembuatan jamban percontohan, tabungan jamban (tanjan) serta pendampingan dilaksanakan sesuai dengan yang telah direncanakan.

2. Pelaksanaan program jamban percontohan dalam kegiatan KKN-PPM mendapatkan respon positif dari masyarakat dan aparat Desa Mengkiang, dimana mereka turut serta berpartisipasi secara aktif mengikuti program dari mulai dilaksanakannya lokakarya mini hingga menerapkan tabungan jamban. Harapannya tabungan tersebut dapat dipergunakan masyarakat untuk membangun jamban secara mandiri di rumah masing-masing, terutama bagi yang belum memiliki jamban.

3. Partisipasi masyarakat dalam kegiatan penyuluhan jamban sehat sebanyak 48

peserta, pendataan rumah tangga yang memiliki jamban sebanyak 69 KK yang tidak memiliki 

jamban (40,67\%) dari $150 \mathrm{KK}$, komitmen membangun jamban percontohan desa bersamasama serta sebanyak 12 keluarga yang berkomitmen mengikuti tabungan jamban (tanjan).

\section{UCAPAN TERIMAKASIH}

Hibah Pengabdian KKN-PPM Kab. Sanggau terlaksana atas pembiayaan Direktorat Riset dan Pengabdian Kepada Masyarakat Kementrian Riset, Teknologi dan Pendidikan Tinggi Tahun Anggaran 2018

\section{DAFTAR PUSTAKA}

[1] UNDP. Human Development Report 2016 Human Development for Everyone. 2016. United Nation Development Programe. New York. http://hdr.undp.org/sites/default/files/2016_human_developm ent_report.pdf

[2]Maskartini. 2015. Peringkat IPM Kabupaten/Kota di Kalimantan Barat. Dimuat di Harian Tribun Pontianak. Senin, $21 \quad$ Desember 2015. Link http://pontianak.tribunnews.com/2015/12/21/ini-peringkatipm-kabupatenkota-di-kalbar

[3]Biro Pusat Statistik Kalimantan Barat. Kalimantan Barat dalam Angka 2016. 2017. Biro Pusat Statistik Kalimantan Barat. Pontianak. Link

https://kalbar.bps.go.id/website/pdf_publikasi/KalimantanBarat-Dalam-Angka-2016.pdf

[4] Biro Pusat Statistik Kabupaten Sanggau. Kabupaten Sanggau dalam Angka 2016. 2017. Biro Pusat Statistik Kabupaten Sanggau. Sanggau. https://sanggaukab.bps.go.id/publication/download.html?nrbv feve=ODYzOTV1MzA5MTRjYjYzYjM3ZDQ0YzUz\&xzmn $=$ aHR0cHM6Ly9zYW5nZ2F1a2FiLmJwcy5nby5pZC9wdWJ saWNhdGlvbi8yMDE2LzA4LzE3Lzg2Mzk1ZTMwOTE0Y2 I2M2IzN2Q0NGM1My9rYWJ1cGF0ZW4tc2FuZ2dhdS1kY WxhbS1hbmdrYS0yMDE2Lmh0bWw\%3D\&twoadfnoarfeau $\mathrm{f}=\mathrm{MjAxOC0xMC0xNSAwNDo0NTo0OQ \% 3D \% 3D}$

[5]Puskesmas Sanggau Kapuas 2016. Profil Kesehatan Wilayah Kerja Puskesmas Sanggau Kapuas Tahun 2015. Puskesmas Sanggau Kapuas. Sanggau. 